\title{
Comparison of the Sealing Efficacies of Two Obturation Techniques in Curved Root Canals Instrumented with and without Ultrasonic Irrigation
}

\author{
Tayfun Alacam ${ }^{1}$, Huma Omurlu ${ }^{1}$, Guliz Gorgul ${ }^{1}$ and Tamer Yilmaz ${ }^{2}$ \\ (Received 3 March 1993 and accepted 23 February 1994)
}

Key words: Thermafil technique, obturation technique, curved canals

\begin{abstract}
Volumetric dye penetration into the canals of 131 teeth was studied spectrophotometrically. The teeth were first divided into three groups according to the degree of curvature. Each group was then subdivided into four groups, in which the Thermafil and lateral condensation techniques were used with or without ultrasonic irrigation.

Significant microleakage differences were observed between group I $\left(0-10^{\circ}\right)$ and group III $\left(21-30^{\circ}\right)$ for lateral condensation filling with ultrasound irrigation and Thermafil filling without ultrasound irrigation $(\mathrm{p}<0.05)$.
\end{abstract}

\section{Introduction}

Lateral condensation with gutta percha is the most commonly used root canal filling technique. However, techniques using warm gutta percha have been gaining popularity. Skinner and Himmel ${ }^{[1]}$ and Johnson $^{[2]}$ described a filling technique utilizing sealer and stainless steel files coated with thermally plasticized $\alpha$-phase gutta percha to obtain three-dimensional obturation of the root canal system. This led to development of the Thermafil system ${ }^{[3]}$.

The objective of canal preparation is to develop a continuously tapering conical form, with the narrowest cross-sectional diameter at its terminus. However, it is not easy to accomplish this shape in curved canals. An hourglass shape and zip at the apex can be commonly observed in preparations of extremely curved canals.

Another parameter of interest is the effect of removal of the smear layer on microleakage from the root canal filling. The ultrasonic method has the advantages of quick debridement, shaping, irrigation, disinfection and obturation. It also plays an effective role in removing the smear layer.

This study used a spectrophotometric method to compare the apical dye penetration observed after obturation by the Thermafil and lateral condensation techniques. The effects of irrigation with and without ultrasonic instrumentation and canal curvature were also evaluated.

\section{Materials and Methods}

One hundred and thirty-one extracted teeth were collected and stored in distilled water at $4^{\circ} \mathrm{C}$. Calculus and periodontal remnants were carefully removed and the crown resected the cemental junction. All roots were between 10 and $13 \mathrm{~mm}$ in length. The teeth were mounted in plaster of Paris blocks, radiographed and root canal curvatures were determined by the Schneider method ${ }^{[4]}$. The teeth were divided into 3 groups based on the degree of curvature (Table 1): Group I, 0-10 degrees; Group II, 11-20 degrees; Group III, 21-30 degrees. The teeth were removed from the plaster blocks and held in a gauze sponge moistened to prevent desiccation during instrumentation and obturation.

1 Department of Endodontics, Faculty of Dentistry, Gazi University

2 Department of Biochemistry, Faculty of Dentistry, Ankara University

To whom all correspondence should be addressed: Dr. Tayfun Alacam, Maltepe Neyzen Tevfik Sok. 36/4 Ankara, TURKEY 
Table 1 Study groups

\begin{tabular}{ccl}
\hline Group & Degree of curvature & Irrigation and Obturation Technique \\
\hline I & $0-10$ & A Ultrasonic irrigation with Thermafil \\
II & $11-20$ & B Conventional irrigation with Thermafil \\
III & $21-30$ & $\begin{array}{l}\text { C Ultrasonic irrigation with lateral condensation } \\
\text { D Conventional irrigation with lateral condensation }\end{array}$ \\
\hline
\end{tabular}

The pulp tissue of each root canal was removed with a barbed broach and biochemical preparation was performed. The apical portions were enlarged through size 45 with hand-held K-type files. A \#15 file was again passed through the apical foramen to assure canal patency. The coronal $3 \mathrm{~mm}$ of the root canal was prepared with Gates Glidden drills (Premier, Norristown, PA), sizes 2 and 3. Copious irrigation with 5.25\% sodium hypochlorite was done throughout the instrumentation procedure. Half of the samples were ultrasonicated, using a Cavitron Model 70011 (Dentsply, 11-40 Borden Avenue, L.I. City, N.Y. 11101, USA) transmitted through a size \#15 file for $3 \mathrm{~min}$ and a \#25 diamond file for $1 \mathrm{~min}$ and allowed to oscillate at a power setting 3 .

A zinc oxide-eugenol sealer was then placed into each root canal. Half of the samples were obturated by the Thermafil method and the other half by the lateral condensation method (Table 1).

Excluding the apical $1 \mathrm{~mm}$, the external surfaces were coated with 2 layers of nail polish and 2 layers of sticky wax. The entire root surfaces of 5 teeth were coated with sticky wax as negative controls. Five teeth whose canals were left empty were used as positive controls.

Each root was suspended in its respective jar over $1 \mathrm{ml}$ of saline solution and placed in an incubator at $37^{\circ} \mathrm{C}$ for $48 \mathrm{~h}$ to allow the sealer to set. The roots were then transferred to new jars, and $1.5 \mathrm{ml}$ of $2 \%$ methylene blue dye was added so that the apical one third of the root was submerged ( $\mathrm{pH}$ 7.1). Again the jars were placed in the incubator for 2 weeks at $37^{\circ} \mathrm{C}$. After removal of the roots, they were rinsed in tap-water for $15 \mathrm{~min}$ and the wax coverings removed. The teeth were then dried with a tissue and left to air-dry for $24 \mathrm{~h}$. The roots were placed into experimental tubes containing $5 \mathrm{ml}$ of $30 \% \mathrm{HNO}_{3}$ for $24 \mathrm{~h}$. Volumetric measurement of dye penetration was then performed spectrophotometrically according to the method developed by Johnson et al. ${ }^{[5]}$ The significance of differences in spectrophotometric values between the groups were determined by analysis of variance and Duncan's test.

\section{Results}

The results for leakage are summarized in Table 2. In group I $\left(0-10^{\circ}\right)$, no significant microleakage differences were found when teeth were obturated by the Thermafil technique, irrespective of whether or not the teeth were irrigated with ultrasonic $(\mathrm{p}<0.05)$. This is available for the lateral condensation technique. Similar results were obtained for group II $\left(11-20^{\circ}\right)$ and group III $\left(21-30^{\circ}\right)$. When teeth were irrigated with ultrasonic and filled with Thermafil, no significant differences were found between the $\left(0-10^{\circ}\right) /\left(11-20^{\circ}\right)$, $\left(0-10^{\circ}\right) /\left(21-30^{\circ}\right)$ and $\left(11-20^{\circ}\right) /\left(21-30^{\circ}\right)$ groups. The same results were obtained for the lateral condensation technique without ultrasonic irrigation $(\mathrm{p}<0.05)$.

For the Thermafil technique without ultrasonic irrigation, no significant differences were found between the $\left(0-10^{\circ}\right) /\left(11-20^{\circ}\right)$ and $\left(11-20^{\circ}\right) /\left(21-30^{\circ}\right)$ groups $(\mathrm{p}>0.05)$ (Tables 3 and 4$)$. However, there were significant differences between the $\left(0-10^{\circ}\right) /\left(21-30^{\circ}\right)$ groups $(\mathrm{p}<0.05)$ (Table 4$)$. Similar results were obtained for the lateral condensation technique with ultrasonic irrigation (Tables 3 and 4 ). 
Table 2 Means and standard deviations of the groups

\begin{tabular}{cccc}
\hline Treatment group & Total No. of teeth & Mean leakage & SD \\
\hline IA & 14 & 28.607 & 28.463 \\
IB & 10 & 32.190 & 27.502 \\
IC & 10 & 28.840 & 24.612 \\
ID & 10 & 30.8 & 28.463 \\
IIA & 9 & 33.133 & 28.529 \\
IIB & 11 & 53.90 & 35.076 \\
IIC & 10 & 43.660 & 24.612 \\
IID & 11 & 47.863 & 37.976 \\
IIIA & 9 & 56 & 27.003 \\
III & 9 & 65.889 & 19.672 \\
IIIC & 9 & 68.511 & 27.502 \\
IIID & 9 & 63.66 & 39.913 \\
\hline
\end{tabular}

Table 3 Statistical analysis of groups IB, IIB and IIIB and IC, IIC and IIIC (analysis of variance)

\begin{tabular}{ccccc}
\hline Treatment group & Sum of square & Degrees of freedom & Computed F value & P \\
\hline IB, IIB, IIIB & 27816.25 & 29 & 3.410 & 0.0468 \\
IC, IIC, IIIC & 25626.36 & 28 & 5.438 & 0.0107 \\
\hline
\end{tabular}

Table 4 Statistical analysis of groups IB and IIIB and IC and IIIC (Duncan's test)

\begin{tabular}{cccc}
\hline Treatment group & T value & F & P \\
\hline IB-IIIB & -3.317 & 1.253 & 0.0041 (2-sided) \\
& & & 0.0020 (1-sided) \\
IC-IIIC & -3.039 & 1.955 & 0.0074 (2-sided) \\
& & & 0.0020 (1-sided) \\
\hline
\end{tabular}

\section{Discussion}

Ingle $\mathrm{e}^{[6]}$, in evaluating endodontic failures in the Washington study, attributed $60 \%$ of all endodontic failures to incomplete obturation of the radicular space. Microleakage above the critical level is considered to cause periapical involvement ${ }^{[6]}$. Therefore, the root filling material and obturation method are important.

The objective of canal preparation is to develop a continuously tapering conical form, with the narrowest cross-sectional diameter at its terminus. However, it is not easy to accomplish this shape in curved canals. An hourglass shape and a zip at the apex are commonly seen in preparations of extremely curved canals. Obturation by the lateral condensation technique can be a problem, especially with instruments greater than $\# 30-35^{[7]}$. Southard et al. ${ }^{[8]}$ showed that the original canal position was maintained $80 \%$ of the time when a size \#40 instrument was used last, but only $40 \%$ of the time when a size \#45 was the first instrument. In order to better compare the obturation of various curved canals, instrumentation to size \#45 was performed. Microleakage examination of curved canals obturated by the Thermafil and lateral condensation methods revealed no statistically significant difference between the two.

Ultrasonic treatment plays an effective role in removing the smear layer. Alacam ${ }^{[9]}$, Cooke et al.$^{[0]}$ and Biesterfeld and Taintor ${ }^{[11]}$ found much more microleakage in Rc Prep-treated samples in their studies of microleakage in teeth whose smear layer was removed. On the other hand, Eldeeb et al. ${ }^{[12]}$ suggested that removal of the apical dentinal plug by irrigation has no effect on further microleakage. Madison and Krell ${ }^{[13]}$ evaluated the apical seal of endodontically treated teeth irrigated with EDTA and $\mathrm{NaOCl}$ using a linear penetration method and found that there was no significant difference between the groups. In our 
study, there was no significant difference between the groups with respect to the irrigation method employed.

However, significant differences in microleakage were seen between group I $\left(0-10^{\circ}\right)$ and group III (21$30^{\circ}$ ) with regard to only lateral condensation filling with ultrasonic irrigation and Thermafil filling without ultrasonic irrigation. That is, leakage increased in accordance with the increase in canal curvature in these groups. In both groups, 21-30 degree specimens showed more dye penetration than 0-10 degree specimens.

Spradling and Senia ${ }^{[14]}$ suggested that unless there is a crack in the cement, methylene blue can not penetrate through the dentine-cement junction and sound cement covering the entire root surface. In this connection we coated the external surface of the roots, excluding the apical $1 \mathrm{~mm}$, with nail polish and wax before submerging them in the dye.

The spectrophotometric method used in this study determined directly the volume of the material that leaked into the radicular space or spaces. Johnson and Zakariasen ${ }^{[5]}$ found that small quantities of leakage were confined to the space between the root filling and the canal wall. This leakage is under capillary control, and volume is assessed from the linear height of penetration (as in a capillary tube). Capillary control is exceeded if higher volumes of fluid leak into the tooth. The water compartments of the dentine are invaded, and the filling material itself may adsorb substantial amounts of fluid. The total volume of leakage is then no longer correlated with the height of the capillary column within the canal. Therefore, in cases of high leakage, total assessment of the endodontic filling material or technique should include spectrophotometric as well as linear measurement of the dye tracer ${ }^{[15]}$.

In our study we limited the root lengths to between 10 and $13 \mathrm{~mm}$ because volume increases as the length increases ${ }^{[16]}$.

According to Eldeeb et al. ${ }^{[12]}$, there appeared to be no statistically significant difference in leakage when the apical constriction was widened to approximately $0.15 \mathrm{~mm}$ in diameter. For this reason we instrumented the foramen using up to \#15 instruments.

In microleakage studies, the sealer is considered to be a variable affecting the results. We used a zinc oxide-eugenol sealer according to the directions of the manufacturer.

Matloff et al. ${ }^{[17]}$ stated that $48 \mathrm{~h}$ of sample immersion in methylene blue was sufficient to determine the maximum leakage. According to Eldeeb et al..$^{[12]}$, the required duration was 16 days, and to Jacobsen et al. ${ }^{[18]}$ it was $72 \mathrm{~h}$. Delivanis and Chapman ${ }^{[19]}$ found that the maximum leakage occurred between 11 and 14 days. Hovland and Dumsha ${ }^{[20]}$ could not find any significant difference between the results obtained in $24 \mathrm{~h}$ and those after $24 \mathrm{~h}, 7$ days and 30 days, although the most significant leakage was seen in the first $24 \mathrm{~h}$. Although the different studies recommended different storage periods, we immersed our samples in methylene blue for 2 weeks.

Direct correlations between dye studies and biological responses have not yet been proved. The quantity of leakage that may not be clinically important is yet to be determined ${ }^{[1,13,21]}$. On the other hand, the level of microleakage at which endodontic therapy can be considered to be successful depends on root canal anatomy, individual tissue tolerance, and the permeability of the dentine, which varies in different teeth. Therefore, the leakage observed in in vitro dye studies should not be considered to represent clinical failure $^{[13]}$.

\section{Conclusions}

1) No significant microleakage differences were found in either group, irrespective of whether or not the teeth were irrigated with ultrasonic and obturated by the lateral condensation or Thermafil technique.

2) When all groups were compared with respect to canal curvature, there was a significant difference in microleakage between the groups with maximum and minimum degrees of curvature (Thermafil and lateral condensation with ultrasonic). In these groups, the leakage increased in accordance with the increase in the difference of the degree of canal curvature.

3) All root canal obturation techniques have individual advantages and disadvantages, and the clinician should examine each case individually. According to the clinical and radiographical indications and 
the shape of the canal preparation, the clinician should choose the most appropriate obturation technique.

\section{References}

[1] Skinner, R.L. and Himmel, V.I.: The sealing ability of injection-molded thermoplastized gutta percha with and without the use of sealers, J. Endodont., 13, 164-169, 1978

[2] Johnson, W.B.: A new gutta-percha technique, J. Endodont., 4, 184-188, 1978

[3] Beatty, R.G.I., Baker, P.S., Haddix, J. and Hart, F.: The efficacy of four root canal obturation techniques in preventing apical dye penetration, J. Am. Dent. Assoc., 119, 633-635, 1989

[4] Schneider, S.W.: A comparison of canal preparations in straight and curved root canals, Oral Surg. Oral Med. Oral Pathol., 32, 271-275, 1971

[5] Johnson, W.T. and Zakariasen, K.L.: Spectrophotometric analysis of microleakage in the fine curved canals found in the mesial roots of mandibular molars, Oral Surg. Oral Med. Oral Pathol., 56, 305309,1983

[6] Ingle, J.I.: Endodontics, 3rd ed., Lea \& Febiger, Philadelphia, 1984

[7] Weine, F.S.: Endodontic Therapy, 3rd ed., C.V. Mosby Co., St. Louis, 1982

[8] Southard, D.W., Oswald, R.J. and Natkin, E.: Instrumentation of curved molar root canal with Roane Technique, J. Endodont., 13, 479, 1987

[9] Alacam, T.: Scanning electron microscope study comparing the efficacy of endodontic irrigation systems, Int. Endodont. J., 20, 287-294, 1987

[10] Cooke, H.G., Grower, M.F. and Rio, C.: Effects of instrumentation with chelating agent on the periapical seal of obturated root canals, J. Endodont., 2, 312-314, 1976

[11] Biesterfeld, R.C. and Taintor, J.F.: A comparison of periapical seals of root canals with Rc-prep on Salvizol, Oral Surg. Oral Med. Oral Pathol., 49, 532-537, 1980

[12] Eldeeb, M.E., Thi Thuc Quyen, N. and Jensen, J.R.: The dentinal plug: Its effect on confining substances to the canal and on the apical seal, J. Endodont., 9, 355-359, 1983

[13] Madison, S. and Krell, K.V.: Comparison of ethylene diamine tetraacetic acid and sodium hypochlorite on the apical seal of endodontically treated teeth,. J. Endodont., 10, 499-503, 1984

[14] Spradling, P.M. and Senia, S.: The relative sealing ability of paste-type filling materials, J. Endodont., $8,543-549,1982$

[15] Johnson, W.T. and Zakariasen, K.L.: Spectrophotometric analysis of microleakage in the fine curved canals found in the mesial roots of mandibular molars, Oral Surg. Oral Med. Oral Pathol., 54, 305309,1983

[16] Ishley, D.J. and Eldeeb, M.E.: An in vitro assessment of the quality of apical seal of thermomechanically obturated canals with and without sealer, J. Endodont., 9, 305-309, 1983

[17] Matloff, I.R., Jensen, J.R., Singer, L. and Tabib, I.A: A comparison of methods used in root canal sealability studies, Oral Surg. Oral Med. Oral Pathol., 53, 203-209, 1982

[18] Jacobsen, E.L., Bedge, E.A., Vitkus, D.D. and Daniel, J.C.: An evaluation of two newly formulated calcium hydroxide cements: A leakage study, J. Endodont., 13, 164-169, 1987

[19] Delivanis, P.D. and Chapman, K.A.: Comparison and reliability of techniques for measuring leakage and marginal penetration, Oral Surg. Oral Med. Oral Pathol., 53, 410-416, 1982

[20] Hovland, E.J. and Dumsha, T.C.: Leakage evaluation in vitro of the root canal sealer cement Sealapex, Int. Endodont. J., 18, 179-182, 1985

[21] Beatty, R.G., Vertucci, F.J. and Zakariasen, K.L.: Apical sealing efficacy of endodontic obturation techniques, Int. Endodont. J., 19, 237-241, 1986 